GRADUATE SCHOOL OF INDUSTRIAL ADMINISTRATION

$$
\text { Reprint No. } 313
$$

\title{
Money Supply Revisited: A Review Article
}

by

Allan H. Meltzer

1967

CARNEGIE INSTITUTE OF TECHNOLOGY Pittsburgh, Pennsylvania 15213 


\title{
Graduate School of Industrial Administration \\ William Larimer Mellon, Founder
}

\author{
Carnegie Institute of Technology \\ Pittsburgh, Pennsylvania 15213
}

\section{REPRINT SERIES}

244. The Effects of Parameter Misspecification and Non-Stationarity on the Applicability of Adaptive Forecasts, by John Bossons. Management Science, May 1966.

245. "A Middlebrow Introduction to Economic Methodology," by Martin Bronfenbrenner. The Structure of Economic Science, 1966.

246. The Treatment of Tax-Exempt Securities in Life Insurance Company Income Taxation. by John Bossons and Jerome E. Hass. National Tax Journal, December 1965.

247. Structural Centrality in Communications Networks, by Kenneth D. Mackenzie. Psychom etrika, March 1966.

248. Observing Stochastic Processes, and Approximate Transform Inversion, by D. P. Gaver, Jr Operations Research, May-June 1966.

249. Factors Influencing Investment in Inventories, by Paul G. Darling and Michael C. Lovell The Brookings Quarterly Econometric Model of the United States, 1965.

250. Interindustry Wage Change Dispersion and the "Spillover" Hypothesis, by Timothy W McGuire and Leonard A. Rapping. American Economic Review, June 1966.

251. The Information Theoretic Entropy Function as a Total Expected Participation Index for Communication Network Experiments, by Kenneth D. Mackenzie. Psychometrika, June 1966 .

252. On the Process of Budgeting: An Empirical Study of Congressional Appropriation, by Otto A. Davis, M. A. H. Dempster, and Aaron Wildavsky. Papers on Non-Market Decision Making, 1966.

253. A Computer Simulation of the Paradox of Voting, by David Klahr. The American Political Science Review, June 1966.

254. Toward a Multi-Stage Information Conversion Model of the Research and Development Process, by Richard G. Brandenburg and Andrew C. Stedry. Naval Research Logintica Quarterly, June 1966.

255. Organizational Planning: Goal Setting in Interdependent Systems, by Robert L. Swinth. Industrial Management Review, Spring 1966.

256. The Wrong Revolution, by Leland Hazard. Columbia Joumal of World Burinare, Summer 1966.

257. Demon: Decision Mapping Via Optimum Go-No Networks-A model for marketing New Products, by A. Charnes, W. W. Cooper, J. K. DoVoe, and D. B. Learner. Management Science, July 1966.

258. A stochastic Model of Supermarket Traffic Flow, by John U. Farley and Lo. Winston Ring. Operations Research, July-August 1966.

259. On Externalities, Information and the Government-Assisted Invisible Hand, by Otto $A$. Davis and Andrew B. Whinston. Economica, August 1966.

260. Some Simple Propositions Concerning Cost-Push Inflation, by William Brainard and Michael C. Lovell. The American Economic Review, September 1966.

261. A Theory of the Budgetary Process, by Otto A. Davis, M. A. H. Dempster, and Aaron Wildavsky. The American Political Science Review, September 1966.

262. A Comparison of Static and Dynamic Correlational Methods in the Study of Organizations, by Victor H. Vroom. Organizational Behavior and Human Performance, August 1966.

263. Statistics vs. Structural Explanations of Understatement and Regressivity in "Rational" Expectations, by John Bossons and Franco Modigliani. Econometrica, April 1968.

264. Collusion, Conflit et Science Economique, by Richard M. Cyert and Lester B. Lave. Economie appliquée, December 1964.

265. A Description and Evaluation of Some Firm Simulations, by Richard M. Cyert. Proceedings of the IBM Scientific Computing Symposium on Simulation Models and Gaming, December 1964

266. A Political Approach to a Theory of Public Expenditure: The Case of Municipalities, by Otto A. Davis and George H. Haines, Jr. National Tax Journal, September 1966.

(Continued on inside back cover) 


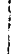

Reprinted from The Jodral of Political Economy Vol. 75, No. 2, April 1967

Copyright 1967 by The University of Chicago

Printed in U.S.A.

$\vdots$ 


\title{
MONEY SUPPLY REVISITED: A REVIEW ARTICLE
}

\author{
ALLAN H. MELTZER* \\ Carnegie Institute of Technology
}

\footnotetext{
$\mathrm{T}$
}

THRTY years have passed since anyone wrote a book exclusively-or even largely-devoted to an analysis of the supply of money. Phillip Cagan's Determinants and Effects of Changes in the Stock of Money, 1875-1960 (1965) ${ }^{1}$ would be welcome, therefore, if it did no more than intensify interest in a subject that lay dormant until recently. The book does much more, however. Cagan patiently examines the multitude of factors that influence the principal determinants of the money supply and hence the money supply itself. He then extracts from his data information about the perennial questions: Do changes in money cause the subsequent changes in output and prices? Or, is the stock of money pulled up and down by secular and cyclical changes in prices and output so that movements of money may be regarded as of little or no causal significance?

These questions have been debated so heatedly that it is refreshing to find an answer that is neither polemical nor assertive. Cagan concludes that the secular movements of the price level can be reasonably interpreted as a response to prior changes in money. Similarly, he finds that severe depressions are caused by a decline in the rate of change of the money stock, although the depression may have been started by nonmonetary factors. The alternative viewthat movements of the money stock are the result of price and output changes-can at best explain a few of the episodes but fails to account for the period as a whole or for

\footnotetext{
* Discussion and joint work with Karl Brunner made an important contribution to the review, and helpful comments from Phillip Cagan clarified several points. Financial assistance from the $\mathrm{Na}$ tional Science Foundation supported the research underlying the review.

1 The title is a slight misnomer; almost all of the data and analysis end with 1955.
}

many of the deep depressions. In mild cycles, however, the evidence that Cagan examined does not permit him to discriminate sharply between the two views. Both processes, stimulus and feedback, are at work, and he concludes that the rate of change of money both influences and is influenced by the behavior of the real sector.

These conclusions and much of the rest of Cagan's discussion make clear that the neglect of the theory of money during most of the past thirty years cannot be explained by the depth or extent of our knowledge. Cagan presents a rich and, at times, imaginative discussion of the factors influencing the money-supply process that differs substantially from the oversimplified versions of "money creation" contained in most textbooks. Frequently, he concludes that we know very little about the forces producing secular and cyclical movements in some of the principal determinants of the money supply-for example, the public's currency ratio and the banks' reserve ratio.

Most of the book develops from a simple formula, given in the first chapter, that relates the money supply (defined as currency plus total commercial-bank deposits of the public) to three determinants. Chapters $\mathrm{ii}-\mathrm{v}$ analyze the combined contribution of the three determinants and examine some of the reasons for the timing of secular and cyclical changes in each. Cagan then uses the information he has assembled to reopen the long-standing disputes about the direction of causality and about the so-called Gibson paradox that has played a prominent role in previous discussions of classical monetary theory.

Unfortunately, the book is uneven. Some problems of little current interest are explored in great detail while others of greater 
interest or importance are neglected. ${ }^{2}$ In part, this is explained by the fact that the book is part of a trilogy ${ }^{z}$ with overlapping subject matter, so that some of the items explored in one book have been largely ignored in another. A more important reason for the uneven approach is the use of the National Bureau procedure, a method that does not appear to be capable of handling multivariate analysis very effectively. And, in part, the framework that Cagan selected caused him to neglect some problems that might otherwise have become apparent. I will develop these points in the following section, then consider his argument about cause and effect in more detail and indicate some differences of interpretation that arise, even if his structure and method of analysis are retained.

\section{THE METHOD AND THE FRAMEWORK}

Reading a National Bureau volume is disconcerting. There always seem to be more characters in the wings than on the stage, and much of the action is hidden from the viewer. Some of the players occasionally dash to the center, take a principal role, then disappear. One wonders where they were before, why they have left, and whether they will return. Others never appear, and we are only dimly aware of their influence. The effect is much like that of watching a series of related dramas, with a large cast of characters, in which the protagonist is not always identified.

Often, the data in a National Bureau volume have been adjusted for intercyclical trend and seasonal factors before they are presented to the reader. The use of cycle

\footnotetext{
2 For example, more space is given to a discussion of the profitability of issuing national bank notes than to the behavior of the Federal Reserve's portfolio or the reasons for the change in the cyclical behavior of high-powered money (reserves plus currency) after 1914. The Treasury's role in smoothing cyclical changes in bank reserves after 1897 is developed in a careful and interesting way, but the accumulation of excess reserves after 1938 is dismissed in a few sentences.
}

s The two other volumes are by Friedman and Schwartz (1963 and forthcoming). relatives, to which substantial attention is devoted and on which main conclusions are based, has an important influence on the results. For example, the dating of peaks and troughs in the series is undoubtedly affected by the Bureau's method. Alternative methods that do not suppress the trend lead to somewhat different conclusions, as I show below.

In addition, the Bureau's method as traditionally applied is not a very useful way of investigating marginal influences. Often we are required to choose between several monistic explanations, based on theories that are never stated completely, or to reject each of the proposed relations. Only rarely are we permitted to reject a particular variable and assign a marginal influence to each of a number of others. For example, Cagan often disposes of an argument by noting that a particular relation does not hold in some of the cycles and must, therefore, be regarded as no more than a chance association when it appears. This is particularly true of his discussion of the factors influencing currency movements and of the relation of bank reserves to interest rates, subjects to which I will return in a later section.

The result is that we are forced to live in a world in which truth is often determined by using a $2 \times 2$ contingency table. Several suggested variables are deemed a priori to be equally effective and equally plausible; they either explain, or they are rejected and replaced by a description of special influences or institutional changes. ${ }^{4}$ Trends and cycles are treated as relatively independent events, and separate explanations are offered for each. The possibility of isolating marginal influences on the money stock that may af-

4 A few examples will illustrate the point. Cagan does not reach a conclusion about the influence of Federal Reserve operations on the money stock. "If we exclude all these special influences, the remaining cycles are too few to support generalizations about Federal Reserve policies" (Cagan, 1965, p. 115). His discussion of long-term swings in the ratio of currency to money ends with a summary of the several influences that operated at different times. His analysis of the secular and cyclical movements of the banks' reserve ratio will be discussed below. 
fect both "trend" and "cycle" is reduced and perhaps eliminated by these procedures. Moreover, cycles are classified as "mild" and "severe," the separation depending upon the magnitude of the downturn following the peak of the reference cycle. $\mathrm{Na}$ tional Bureau cycles are usually measured from trough to trough, so that a "severe" cycle often includes the recovery from a "mild" cycle. I find this procedure strange. Economic theory implies that the economy moves toward full use of resources and thus suggests that the size of the recovery is more closely related to the preceding than to the following recession. On this line of reasoning, "severe" and "mild" cycles should run from peak to peak. The influence that Cagan's classification has on his conclusions can only be judged by recomputing the results reported in his many tables. Since I did not make the calculations, I can only enter a caveat.

The decision about the size of the trend, and hence about what is called cyclical, depends of course on the definition of money that is chosen. Cagan's definition-currency plus total commercial-bank deposits, which I will denote by $M_{2}$-has a larger growth rate for the period as a whole than the narrower definition $\left(M_{1}\right)$ that excludes time deposits at commercial banks. Moreover, $M_{2}$ and $M_{1}$ have very different growth rates during some of the subperiods in which data on time deposits are available. It is surprising, therefore, to find that Cagan makes no attempt to compare the movements of $M_{1}$ and $M_{2}$ or to analyze the effect of shifts between demand and time deposits on the cyclical movements in money.

The effect of shifts between the two classes of deposits is mentioned only in the Introduction and in a chapter devoted to the banks' reserve ratio. In a brief defense of his choice of definition, Cagan (1965, pp. $3,167,171-72)$ refers to the problem of separating time and demand deposits prior to 1917 and perhaps in the twenties as well. L. Currie, who compiled a series on money for the twenties from the closer perspective of the early thirties, discussed the shift from demand to time deposits in the twenties and concluded: "The Committee presented no evidence of the alleged shift of large corporation demand deposits to the time classification since the war. Mr. D. R. French, who has carefully analyzed the available data, found no evidence of such a shift" (Currie, 1935, p. 17). Cagan (1965, pp. 171-72) cites French also and accepts the conclusion that there is no evidence that banks encouraged large corporate depositors to shift into time deposits. ${ }^{\circ}$ Since the main problem of separating time and demand deposits appears to be in the data for the years prior to 1917, a separate analysis of $M_{1}$ and $M_{2}$ would have been desirable.

One important influence of the choice of definition comes when Cagan attempts to analyze the separate influence of his three determinants of changes in money. Changes in the ratio of time to demand deposits affect the two stocks of money in opposite ways and by unequal (absolute) amounts. I will give some indication of the difference this makes after presenting the framework that Cagan used.

Cagan's analysis starts from two definitions. Money is defined as currency held by the public $(C)$ and total deposits at commercial banks $(D+T) .^{7}$ The government's contribution, the monetary base or highpowered money, $B$, is the sum $C+R$, where $R$ is bank reserves including vault cash. Each dollar of high-powered money raises the money supply, $M_{1}$ or $M_{2}$, by a multiple that depends on prevailing legal or institutional arrangements and the decisions

- The committee referred to is the Federal Reserve's Committee on Member Bank Reserves which reported in 1931. Cagan also cites the article by French (1931).

- Note that French and Currie do not deny that there was a shift from demand to time deposits. The point at issue is whether the two types of deposits are separated reliably in the existing data, hence the reference to the "alleged shift."

'I have used $D$ for demand deposits and $T$ for time deposits in place of Cagan's use of $D$ for the sum of the two. 
of the banks and the public. As Cagan emphasizes, the two definitions imply that

$$
M_{2}=\left(\frac{1}{C / M_{2}+R / M_{2}}\right) H,
$$

where the first expression on the right is the multiplier. Cagan then rearranges the equation slightly and defines the multiplier as

$$
\frac{1}{C / M_{2}+[R /(D+T)]\left(1-C / M_{2}\right)} \text {. }
$$

He refers to $C / M_{2}$ as the currency ratio and $R /(D+T)$ as the reserve ratio. Much of

TABLE 1

RANK CORRELATIONS BETWEEN GROWTH RATES OF MONEY, HIGH-POWERED MONEY, AND THE MULTIPLIERS DURING HALFCYCLES, 1919-1964

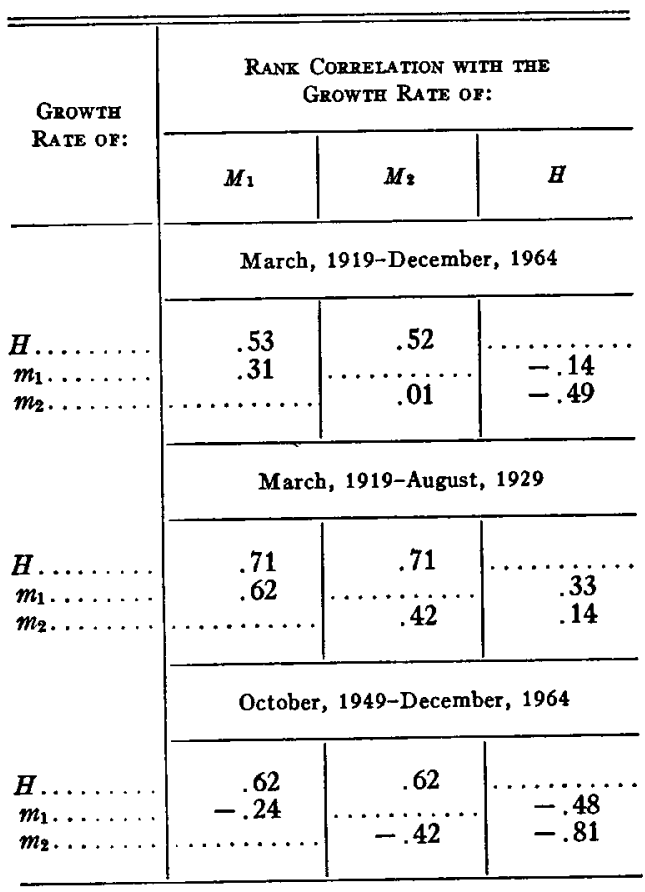

the rest of the book is an elaboration of the secular and cyclical movements in $H$ and the two ratios and of the factors that influenced them at various times.

The fact that the monetary multiplier can be expressed in the way Cagan did should not suggest that this is a particularly useful way, and I do not believe that it is. First, as noted above, the influence on money of changes in the ratio of time to demand or to total deposits is hidden in the currency and reserve ratios. Second, by expressing currency in relation to $M_{2}$, Cagan's formula suggests that the volume of currency held depends on the volume of time deposits. ${ }^{8}$ This means that the currency ratio must change if there are portfolio changes that raise or lower time deposits, even if the volume of currency and demand deposits remains unchanged.

Some indication of the difference made by the choice of definition is shown by the data in Table 1. Each definition of money was expressed as the product of a multiplier, $m_{1}$ or $m_{2}$, and the monetary base or highpowered money. The ratio of the terminal stock of money to the beginning stock of money was computed for half-cycles during 1919-64 and rank correlated with the ratio of terminal value/initial value of $B$ and of the relevant multiplier. The results suggest that during the period as a whole and in the twenties the changes in $M_{1}$ are more highly correlated with changes in $m_{1}$ than are changes in $M_{2}$ correlated with $m_{2}$. Moreover, the correlations between the growth rates of $m_{2}$ and $H$ are appreciable, particularly in the fifties. ${ }^{9}$ Differences in the growth rates of the two multipliers are solely the result of the different effects of changes of the ratio of currency to demand deposits and of the ratio of time to demand deposits. Both ratios are part of Cagan's currency ratio. The rank correlations suggest that the framework and the definitions influenced Cagan's results. One likely result is that he

${ }^{8}$ This is shown most easily using the reciprocal of Cagan's currency ratio, $M_{2} / C=1+D / C+$ $T / C$.

- The low correlation between the growth rates of $m_{2}$ and $\boldsymbol{H}$ in the twenties is due to the effect of member-bank borrowing. The result for the various periods are more uniform if member-bank borrowing is subtracted from high-powered money and the multipliers are appropriately redefined. The rank correlation of the appropriate multiplier and the adjusted monetary base (adjusted high-powered money) is always larger in absolute value when money is defined as $M_{2}$. For the three periods shown in Table 1 , the rank correlations are $-.56,-.71$, and -.62 when borrowing is excluded from $B$. 
understated the influence of changes in the demand for currency on the rate of change of money. I will return to this point in the following section. Before doing so, one additional problem about his method should be mentioned.

Cagan (1965), following Friedman (1961) measures the lag of outpul behind money by comparing peaks and troughs in the rate of change of money with peaks and troughs in the level of economic activity. This procedure has been criticized by a number of writers, ${ }^{10}$ and most trenchantly by J. Kareken and R. M. Solow (1963). Kareken and Solow show that one can reach any conclusion about leads and lags between money and economic activity by comparing changes in the rate of change of one of the variables with the rate of change of the other. The lead of money over economic activity virtually disappears if turning points in money are substituted for turning points in the rate of change of money.

Cagan agrees that "evidence on timing cannot be decisive on the direction of influence" (1965, p. 5) but defends his procedure on two grounds. First, he shows that the amplitudes of monetary and business cycles are highly (rank) correlated and argues that the correlation reflects causation running from the cycles in money to subsequent cycles in economic activity. This argument begs the question. Since the amplitudes of rates of change in money and rates of change in output are correlated also, the use of rates of change for both variables would retain the correlation but eliminate the persistent long lead-twelve to eighteen months on the average - shown by turning points in the rate of change of money. Second, Cagan suggests a theory of the cycle, akin to the argument implicit in $A$ Monetary Bistory of the United States, 18671960 (Friedman and Schwartz, 1963), ${ }^{11}$ in which major departures from equilibrium occur because of variations in the rate of

\footnotetext{
${ }^{10}$ See particularly J. M. Culbertson (1960).

11 For an attempt to state the theory explicitly, see my review article (Meltzer, 1965).
}

change of money. The argument seems to say that the economy will stay near full employment and the price level will adjust to any maintained rate of change of money, although mild departures from full employment will occur for a variety of non-monetary reasons. However, changes in the rate of change of money are not absorbed immediately by changes in the price level. In the short run, such changes affect the level of output, presumably through their effect on interest rates and other relative prices; in the longer run, the price level rises or falls, and output returns to the full-employment range.

The second argument bypasses the methodological criticism but does not answer it. While Cagan's partial explanation of cycles is sufficiently interesting to be judged on its merits, tentative acceptance of the theory does not require acceptance of his conclusion about the length of the lag in monetary policy. The reason is that the theory makes the money supply depend on output and other endogenous variables. Cagan suggests that, during mild cycles, the endogenous variables are the most important determinants of the rate of change of money; the influence of monetary policy on money is found to be small and irregular. Unless it is assumed that the Federal Reserve judges the size or direction of monetary policy by the rate of change of money, the lag of output behind the rate of change of money and the lead or lag relation between policy variables and money should be treated separately. The former depends on the structure relating money and output; the latter depends on the way in which policy decisions are made and on the structure relating policy variables to money.

Despite these lengthy criticisms of both the structure and the method of analysis, I will retain both in the following sections. While many of Cagan's conclusions may depend heavily on his use of the NBER method, some appear to be of doubtful validity even if that method is retained. I have, therefore, retained the method so that differences in our conclusions will not depend on methodology. 
THE ROLE OF THE CURRENCY RATIO

Most explanations of the behavior of money during business cycles assign primary responsibility for monetary change to the monetary authorities or to the behavior of the banks. Cyclical changes in the currency ratio are generally regarded as important only in periods during which the public converts a large fraction of its deposits into currency, although recent studies have suggested that changes in the demand for currency should not be totally neglected at other times (Brunner and Meltzer, 1964a; de Leeuw, 1965).

Cagan's conclusion (1965) is the opposite of these more familiar conclusions. He found that changes in the currency ratio are a more important and a more regular source of cyclical changes in the growth rate of money than changes in the banks' reserve ratio or in high-powered money. In the eighteen reference cycles between 1877 and 1954 , changes in the currency ratio accounted for 50 per cent of the cyclical variation in the growth rate of money, $M_{2}$. These findings led Cagan to propose a theory of the cycle in which changes in the currency ratio and their effect on the growth rate of money play a dominant role. In this section, I will restate his argument and discuss some qualifications. In the following section, I present an alternative interpretation of his findings that assigns more responsibility to the traditional culprit-the central banker. Since the principal differences in interpretation concern mild cycles, most of the discussion neglects severe or major cycles.

The facts are relatively clear. $C / M_{2}$ generally reached a maximum rate of decline, relative to trend, well before the reference peak and a minimum rate of decline, relative to trend, well before the reference trough. As a result, the contribution of the currency ratio to the rate of change of the money stock during mild cycles was smallest at the reference peaks and largest at the reference troughs.

After examining some alternative interpretations, Cagan concluded that "business cycles were set in train by changes in the money stock and, in turn, produced cor- responding movements in the currency ratio" (1965, p. 275). The importance for this interpretation of the magnitude and timing of the changes in the currency ratio is revealed by the following quotation:

The peak in the monetary growth rate typically comes during the first part of business expansions. The ensuing decline in the rate reflects decreasing contributions from the currency and reserve ratios, primarily the former. ...

High-powered money behaves irregularly during business expansions, but, more often than not, its growth rate at first expands and then subsides during this phase. On net, the rate of change in the money stock falls steadily until there is a peak in business activity, or somewhat later. Then monetary growth begins to rise, reflecting an upturn in the contribution of the currency ratio and irregular contributions by the other two determinants that tend to cancel each other.... The cycles in money can be attributed to all three determinants, though most consistently for the entire period to the currency ratio, and for the later period more so to highpowered money than to the reserve ratio [Cagan, 1965, pp. 287-88].

Since it is Cagan's tentative conclusion that the cyclical behavior of the currency ratio may be explained as a lagged response to consumer expenditures and wealth (1965, pp. 150, 293), the outline of his argument about cause and effect during mild cycles can be stated as follows: (1) The currency ratio responds with a lag to income or expenditures. (2) The rise or fall of the currency ratio accelerates or decelerates the rate of monetary growth. (3) Changes in monetary growth induce changes in the growth rate of output. (4) The irregular behavior of high-powered money and the reserve ratio alters the timing and the magnitude of the response in output.

This brief description indicates the channels through which income influences the rate of change of money and the way in which the rate of change of money influences the rate of change of output. It is the foundation for Cagan's conclusion that during mild cycles the public, rather than the central bank, has the dominant influence on the rate of change of money.

Even if the Federal Reserve or the 
Treasury (in the years before 1914) has had little interest in the growth rate of money, Cagan's conclusions about the importance of cyclical changes in the currency ratio are startling. One main purpose of the Federal Reserve Act was to offset the effect of changes in the demand for currency on output. Yet Cagan's data show that the Federal Reserve permitted the amplitude of the fluctuations in currency to increase substantially. The relevant data, computed from his Table 14, are shown in Table 2.

The data in column (1) show that, after reaching a peak in Stage III, the downward trend in $C / M_{2}$ is generally suspended, and the currency ratio remains level or rises slightly until Stage VII. Columns (2) and (3) suggest that the amplitude of the fluctuations in the currency ratio was much larger in the seven non-war cycles after the Federal Reserve was established. The same conclusion appears to hold for the non-war Federal Reserve cycles even if the severe cycles of the 1930's are omitted. ${ }^{12}$ The increased amplitude of the change in the currency ratio during Stages I-V and VII-IX means that the contribution of the currency ratio to the rate of change of money was larger, given the other determinants, after the Federal Reserve was established.

I will discuss three explanations of the increased amplitude of the currency ratio after 1919. The first two consider and reject the possibility that the increased amplitude is solely the result of Cagan's framework. The third, an alternative explanation of the behavior of money after the Federal Reserve was established, is discussed in the following section.

One explanation is that changes in the currency ratio are highly correlated with changes in high-powered money so that the influence that Cagan assigned to the currency ratio more likely reflects the influence

\footnotetext{
12 The table probably overstates the magnitude of the change. The pre-1914 averages are based, in part, on annual rather than monthly observations and hence have smaller amplitude. This qualification does not affect the conclusion about changes in the relative contribution of changes in the currency ratio discussed in the next sentence of the text.
}

of changes in high-powered money by the central bank. This explanation is only partly correct. Cagan finds that the contributions of the currency ratio and high-powered money to the trend-adjusted rate of change of money are correlated, but the correlation is in the neighborhood of -.3 . He concludes that part of the erratic movement in highpowered money is the result of changes in $B$ designed to offset changes in the currency

TABLE 2

Changes in CuRrency Ratio duRING REFERENCE CYCLES 1879-1954

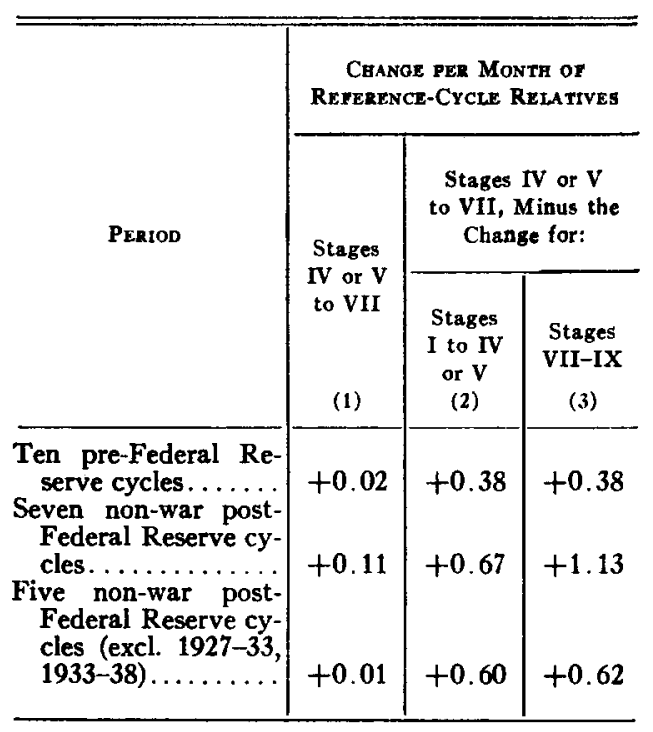

Source: Cagan (1965, Table 14, p. 138).

and reserve ratios. After a careful and thorough discussion of the problem of adjusting the relative contributions to eliminate the Federal Reserve's attempt to offset changes in the two ratios, he concludes that the influence of high-powered money increased after 1914. For Stages III-VI of the cycle in the rate of change of $M$, highpowered money was the most important of the three; in Stages VII-II, high-powered money and the currency ratio each produced half of the cyclical variation in money (Cagan, 1965, p. 43).

This conclusion is puzzling, and Cagan's interpretation seems strange. Why does the Federal Reserve or $B$ dominate the behavior 
of money before and after the peak in the growth rate of money but not before and after the trough? Why do they offset most of the movements in the two ratios during some phases but not in others? If his explanation is accepted, the problem posed by the increased importance of the currency ratio in cycles after 1919 is at most reduced to the problem of explaining the increased importance of the currency ratio during part of the cycle.

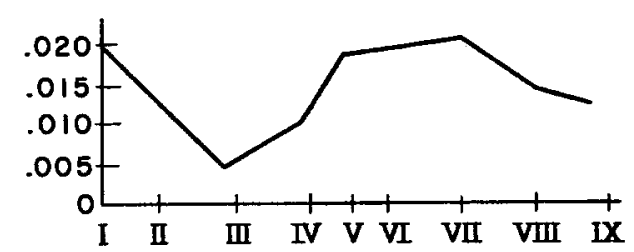

FIG. 1.-Differences in the percentage rate of change of $m_{2}$ and $m_{1} . \Delta m_{2} / m_{2}-\Delta m_{1} / m_{1}$. Four mild cycles (1921-24, 1924-27, 1945-49, 1949-54).

A second explanation attributes Cagan's findings to his definition of the currency ratio, as mentioned earlier. If the time-deposit component substantially alters the rate of change of $M_{2}$ or of $C / M_{2}$ during cycles, Cagan's result may reflect his choice of definitions. The conclusion may not hold for the ratio $C / M_{1}$.

The effect on his currency ratio of changes in time deposits becomes apparent if we express the reciprocal of his currency ratio, $M_{2} / C$, as the sum $(1+D / C)+T / C$ and examine the movements of the two components. Between 1914 and 1960, approximately one-third of the annual changes in the two ratios were in opposite directions. In eleven of the years that show movements in the opposite directions, the reference cycle reached a peak or a trough, so it seems reasonable to conclude that the two ratioshence $D$ and $T$-behave differently at or near turning points in economic activity.

Additional evidence is obtained by using a procedure similar to Cagan's. $M_{1}$ and $M_{2}$ can be expressed as the product of a multiplier, $m_{1}$ or $m_{2}$, and the common multiplicand, $H$. The equation for $M_{2}$ is then identical to Cagan's and differs from $M_{1}$ because of the different effects of changes in the ratios of currency to demand deposits and of time to demand deposits on the two multipliers.

Figure 1 shows the average difference in the relative growth rates of the two multipliers at each of the nine stages of mild NBER reference cycles during the period for which Milton Friedman and Anna Schwartz report separate estimates of demand and time deposits. ${ }^{13}$ The difference in the relative growth rates,

$$
\frac{\Delta m_{2}}{m_{2}}-\frac{\Delta m_{1}}{m_{1}}=\frac{T}{M_{2}}\left(\frac{\Delta T}{T}-\frac{\Delta M_{1}}{M_{1}}\right),
$$

has a reference-cycle pattern very similar to the deviations of Cagan's (1965) $C / M_{2}$ from trend that are shown in Figure 2. The data suggest, therefore, that the relative rates of change of $M_{1}$ and $T$ are approximately the same only in Stage III of reference cycles. The difference between the relative growth rates rises until long after the peak of the reference cycles, then falls from Stage VII to Stage III of the following

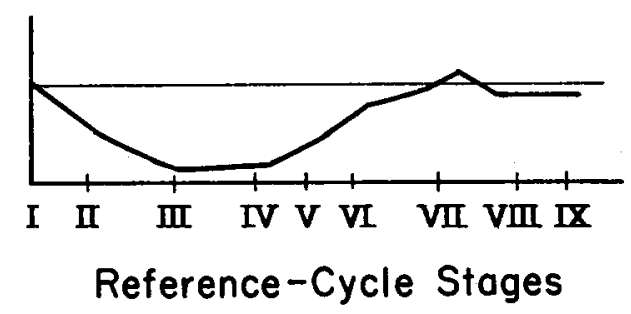

Fig. 2.-Deviations of $C / M_{2}$ from trend. Ten non-panic cycles taken from Cagan's Chart 11 (1965, p. 135).

mild cycle. The minimum contribution of $\Delta T / T$ to the difference in the relative growth rates of the two definitions of $M$ comes at Stage III, and the maximum

13 To avoid the possibility that my results might be affected by the recent behavior of money or by the relatively large increases in time deposits in recent years, I did not include the period after the trough in August, 1954, in the calculations. Most of Cagan's data ends with this cyclical trough also. The relative rates of change were computed by dividing changes in $m_{1}$ and $m_{2}$ during each twelve-month span by the value of $m_{1}$ or $m_{2}$ in the twelfth month. 
contribution is at Stage VII. The cyclical pattern in the relative growth rate of time deposits raises the growth rate of $M_{2}$ relative to the growth rate of $M_{1}$ from Stage III to Stage VII and thus lowers $C / M_{2}$ relative to $C / M_{1}$. These are the stages in which Cagan finds that $C / M_{2}$ declines relatively little and makes the smallest contribution to the growth rate of $M_{2}$. In Stages VII-III, during which $C / M_{2}$ makes its largest contribution to the growth rate of $M_{2}$, the growth rate of time deposits has the opposite effect. It reduces the difference between the growth rates of $M_{2}$ and $M_{1}$ and raises $C / M_{2}$ relative to $C / M_{1}$. Thus the effect of time deposits on $C / M_{2}$ is reduced (or offset) by other components of the ratio. Cagan's findings about the amplitude of the currency ratio cannot be explained in this way. ${ }^{14}$

\section{THE FEDERAL RESERVE, THE CURRENCY RATIO, CAUSE AND EFFECT}

The increased variability of the currency ratio after the Federal Reserve was established can be explained by assigning most of the responsibility for past variations in the currency ratio and in the rate of change of money to monetary policy. In this section, I will outline an alternative explanation that is broadly consistent with Cagan's findings but suggests an entirely different interpretation of "cause and effect."

Suppose that the Federal Reserve pays little or no attention to the growth rate of money, however defined. Cyclical changes in the growth rate of money are regarded as unimportant, and principal attention is focused on "money-market conditions"-on interest rates and changes in bank credit. Positive or rising free reserves and lower money-market rates are interpreted as an indication of "easier policy" and negative or

\footnotetext{
${ }^{14}$ This should not suggest, however, that changes in $m_{2}$ during half-cycles are always smaller than changes in $m_{1}$. The text discusses the effect on $M_{2}$ of defining the currency ratio as $C / M_{2}$. It does not discuss the relative effects of changes in currency and time deposits on the two definitions of money. For more detailed discussion of the relative effects, see Karl Brunner and A. H. Meltzer (1964c).
}

falling free reserves and higher interest rates of a "tighter policy."

There is abundant evidence that the framework just described represents the main features of the Federal Reserve's approach to monetary policy (see Brunner and Meltzer, 1964b). For many years after 1914, the Federal Reserve did not publish-and most likely did not collect-statistics about the money supply or its growth rate. There is very little evidence that they have ever regarded movements of the money supply as of more than passing interest.

If the lag, or delay, between monetary policy and changes in free reserves and in market interest rates is very short, we would expect interest rates to reach a peak or trough very near the peak or trough in the reference cycle. This is precisely the pattern that is shown by short-term interest rates during mild cycles after 1919.15 On my interpretation, the cyclical movements of interest rates reflect the Federal Reserve's early recognition of turning points in economic activity, prompt action that they believe to be countercyclical, and an inconsequential lag between policy decisions and their effect on short-term interest rates.

Cycles in money or its growth rate are, then, not fully explained by the effect of changes in expenditure on the currency ratio and the subsequent effect of changes in the currency ratio on the rate of change of money. The finding that $C / M_{2}$ makes a minimum contribution to the rate of change of money at the peak and a maximum contribution at the trough means that $C / M_{2}$ has the opposite effect on interest rates during reference cycles, raising them at the peak and lowering them at the trough. In the Federal Reserve's framework, the pattern in the currency ratio is part of the mechanism producing the policy they regard as countercyclical, although they may be unaware of the contribution that the currency ratio makes. If the cyclical influence of the currency ratio on $M_{2}$ were offset completely, less high-powered money would be issued

\footnotetext{
${ }^{15}$ Reference-cycle patterns for interest rates are from Cagan (1966).
} 
from Stages VII to II of the reference cycle, and the fall in interest rates would be retarded or reversed.

The Federal Reserve's concentration on interest-rate movements helps to explain some of the puzzling features of Cagan's discussion. First, the use of interest rates as an indicator of policy suggests a reason for the continued (and possibly increased) importance of variations in the currency ratio after 1919; second, it provides an interpretation of the correlation, discussed earlier, between the contributions to monetary growth of high-powered money and the two ratios; third, it provides an explanation of the irregular reference-cycle pattern in highpowered money.

Cagan found that the contributions of $H$ and of the two ratios to the rate of change of money are more negatively correlated during Stages III-VI (-.74) than during Stages VII-II $(-.51)$ of the cycle in money. His regression coefficients for the separate periods are -.89 and -.28 , respectively, suggesting that, near the peak, movements of $H$ offset the largest part of the effect of the two ratios on the rate of change of money. Near the trough, there is very little offset. Prior to the establishment of the Federal Reserve, $\boldsymbol{H}$ offset a more nearly uniform proportion of the effect of the two ratios at all phases of the (average) cycle in the growth rate of money. The advent of the Federal Reserve resulted in an increase in the proportion offset at the peak and during the late expansion and a reduction in the proportion offset at the trough and in the late contraction. As a consequence, the lag of short-term interest rates was reduced and virtually eliminated at the peak of the reference cycle and became slightly longer (but remained inconsequential) at the trough. The average lag of long-term interest rates was reduced substantially at both peak and trough (Cagan, 1966).

Improved conformity of market interest rates with the reference cycle was obtained at the price of increased contribution of the currency ratio to the rate of change of money. A smaller part of the change in the cur- rency ratio is offset before and after the trough of the cycle in the growth rate of money (from Stages VII to II) because the decline in the currency ratio contributes to a fall in interest rates during this part of the recession in economic activity (or reference cycle).

The irregular reference-cycle pattern for high-powered money can be explained in much the same way. To obtain improved conformity of interest rates during reference cycles, the Federal Reserve allows $B$ to vary in a way that maintains the cyclical pattern in interest rates. The currency ratio does part of the work, provided its contribution in the downswing (to the rate of change of money) is offset less than it was in the period before 1914. The Federal Reserve has never constructed a series on $H$, never mentions the sum reserves plus currency in any public statement, and is, most likely, unaware of the change in the cyclical pattern of $H$. The principal instrument of monetary control has an irregular pattern of deviations from trend because it has been neglected and has become a residual element in the determination of market interest rates.

The irregularity of the cyclical pattern in $H$ is increased by the Federal Reserve's traditional concern for seasonal, random, and often self-reversing changes in free reserves and short-term interest rates. Their attempt to remove seasonal and random influences on market interest rates makes the changes in high-powered money and in money far more variable than they would otherwise be. It is likely that this policy increases the variability of changes in $H$ relatively more than changes in $M$ (Brunner and Meltzer, 1964b). Even if all of the seasonal changes in $H$ are removed, a large random component would remain in the cycle relatives of $H$. But it is unlikely that seasonal changes in $H$ designed to remove seasonal changes in interest rates can be easily separated from random movements in the monthly data that Cagan used (1965). They are an additional source of irregular changes in $B$ at particular stages of the cycle. 
On the average, changes in $H$ have a pronounced countercyclical pattern in the reference cycles from 1879-1914 and a dominantly procyclical average pattern from 1919 to 1954 (Cagan, 1965, Chart 7, p. 102). Cagan is unable to explain this change in the movements of $B$ within his framework, and he failed to consider the alternative explanation presented here. My explanation appears to account for the average pattern, and for the irregularity of the changes as well. Both would result from the Federal Reserve's concentration on market interest rates and not on changes in $\boldsymbol{H}$ or in money, if $H$ is required to vary enough to offset undesired changes in other determinants of market interest rates.

This explanation makes Federal Reserve policy-and not the currency ratio-the dominant influence on money. It suggests that Cagan's discussion of "cause and effect" may be correct as far as it goes but that it does not go far enough. The Federal Reserve's neglect of the behavior of money and concentration on the movements of interest rates becomes the principal "cause" of the cycle in money.

Let me state the alternative explanation more fully. During the upswing, the demand for bank credit and interest rates on the money and credit market are rising. The Federal Reserve allows reserves or highpowered money to increase, certain that rising interest rates (and falling free reserves) indicate that a more restrictive policy is in effect. Cagan's currency ratio stops declining in Stage III, increasing the pressure on the money market. A decline in the demand for credit, and an accompanying decline in interest rates once the peak is passed, convinces the Federal Reserve that its policy has become more expansive, despite the rather steady decline in highpowered money, or in its rate of growth, that continues to the reference-cycle trough. The renewed fall in the currency ratio, starting in Stage VII, reinforces the belief that policy-judged by market interest rates-has shifted to "active easing" and that monetary policy is doing its best to promote recovery. Eventually, the bottom is reached, in part because the decline in the currency ratio dominates the behavior of money and the money supply (or its growth rate) starts to rise.

This interpretation of the cycle in the growth rate of money finds support in Cagan's data. It explains why the peak in the cycle relative of $B$ from 1914 to 1954 comes either at, or before, the reference peak in eight of the nine cycles and why the trough in the cycle relatives of $H$ comes at the trough of the reference cycle seven of nine times. It explains the much greater amplitude of the "non-gold" sources of $H$ after 1914, findings for which Cagan offers only a series of "special reasons." 16 It explains why the peaks and troughs in the rate of change of money and in interest rates are much more regular in their timing than the peaks and troughs of changes in $B$ or in the two money multipliers. And it partly explains why a large or variable number of months between the peak rate of change of money and the peak of the reference cycle has very little bearing on the length or variability of the lag in monetary policy.

My discussion of the cycle in money, though broadly consistent with Cagan's findings (1965), suggests a very different interpretation of the causes underlying changes in money. The Federal Reserve's policy of concentrating on a narrow corner of the money market becomes a principal "cause" of the amplitude of fluctuations in money or its rate of change and thus a cause of fluctuations in output and its rate of change. Neglect of the cycle in money becomes a principal cause of the cycle in money; the cycle in output is an important "effect."

\section{SOME ADDITIONAL COMMENTS}

Throughout the review, I have concentrated on the method, the framework, and the discussion of cause and effect. I believe that there is a relation between the three, since Cagan's structure and method of

16 See Cagan (1965), p. 103 for the data, pp. 11516 for the explanations. 
analysis focused his attention too narrowly on the currency ratio at the expense of a broader interpretation of the role of the monetary authority. My discussion of the book would be misleading, however, if it failed to mention some of his other findings, many of which are related to the causal role of money but not to the effect of income on money. Much of his analysis is detailed, careful, informative, and worthy of attention. I will briefly discuss a few of his more important or more provocative conclusions in this section.

During most of the period considered in Cagan's book, the United States was on a gold standard, a de facto standard from 1879 to 1900 , a legally established standard from 1900 to 1933. However, gold flows do not account for all of the secular or cyclical changes in money or high-powered money in either period. The Treasury, after 1897, made an effort to offset seasonal and cyclical changes in the banks' reserve ratio by depositing or withdrawing balances at national banks. Cagan's informative analysis shows that the Treasury accepted the responsibility of a central bank well before the Federal Reserve was established and suggests that the concern for money-market conditions was well established in the United States before 1914.

Nevertheless, gold movements dominate the longer-run movements in the base prior to the establishment of the Federal Reserve. Changes in the gold stock accounted for approximately two-thirds of the annual changes in high-powered money before 1915 and two-fifths of the annual changes from 1915 to 1955 . Although percentage changes in the gold stock were much larger after 1914 , they account for a much smaller proportion of the changes in high-powered money. The Federal Reserve had much more power to alter the stock of highpowered money than the Treasury, and they used the power, particularly during wartime periods.

Cagan's analysis of changes in the gold stock applies the purchasing-power-parity theory. Changes in money cause changes in domestic prices in the same direction, which in turn lead to changes in the gold stock and in foreign prices. These ultimately reverse the gold flow and the direction of change in the quantity of money. Cagan finds that this process operates with an extremely long lag-measured in decades-so that the mechanism is unreliable as a means of stabilizing the price level in the short run. There are excellent discussions of the operation of this mechanism during several periods and of the important evidence that it provides about the effect of changes in the quantity of money as an independent source of changes in output and the price level.

One of Cagan's more intriguing results is that the ratio of high-powered money to the gold stock has shown substantial swings but has often returned to a value of 2 . Since large swings in the ratio appear to be related to changes in the commodity value of gold in the opposite direction, he interprets the findings as broadly consistent with a commodity theory of money and a long lag. On this interpretation, the United States has been moving away from the equilibrium achieved in 1952 when the ratio of $H$ to the gold stock was 2.03 and the index of the commodity value of gold was about $1 .{ }^{17} \mathrm{My}$ computations suggest that by the end of 1965 the ratio reached 4.3 and the index of commodity value had declined to 0.88 . A 14 per cent increase in the price of gold (to forty dollars) would restore the value of the index to unity, raise the value of the U.S. gold stock, and thus lower the ratio of high-powered money to gold.

However, the 14 per cent increase in the dollar price of gold would leave the ratio of $H$ to the gold stock well above 2. An inflow of $\$ 24$ billion of gold (at the new price) would be required to restore the ratio to 2 . The size of the required gold inflow seems large relative to the world stock of gold, even at the higher price of gold. If the calculation is correct, it suggests that the imbalance of payments is likely to remain for

\footnotetext{
${ }^{17}$ Following Cagan, $I$ used the wholesale-price index, base $1926=100$, for the index of dollar prices of commodities.
} 
a long time in the absence of a substantial change in the price of gold, an increase in gold production, or large changes in foreign prices relative to U.S. prices.

The careful discussion of crises, panics, and the suspension of payments should also be mentioned. Cagan found that the currency ratio had much the same pattern in mild and severe cycles. Currency drains or bank runs usually come along after the peak of the cycle and thus cannot account for the turning point, although the drains often intensified the financial crisis.

Cagan concludes that "all sudden large increases in the currency-money ratio during peacetime have reflected banking panics, stemming from expectations that banks might suspend payments" (1965, p. 139). In fact, payments were suspended in six of the eighteen non-war cycles when banks attempted to maintain their solvency and prevent failure. The record suggests that the banks were successful at times. High failure rates occur in only three of the cycles in which banks suspended payments, and suspension of payments in three cycles was not accompanied by a high failure rate. The difference is accounted for, in part, by the willingness of the banks to issue "illegal" substitutes for currency and clearing-house certificates, in part by the fact that high failure rates occurred in the middle twenties for reasons unrelated to the suspension of payments.

The most disappointing section of the book is the lengthy discussion of the reserve ratio. Here, the separation of secular from cyclical, the use of cycle relatives, and the $2 \times 2$ "contingency table" approach had too much influence on Cagan's conclusions. The effect of interest rates on banks' desired reserve ratios is dismissed, separately, in discussions of secular and cyclical movements. The data used to arrive at the conclusion are not adjusted for changes in the ratio of time to demand deposits. The effect of the time-deposit ratio on the reserve ratio is treated separately and is said to be of little importance-despite computations showing that the three swings in the time- deposit ratio account for one-sixth to onethird of the change in the reserve ratio during the three periods he discusses (Cagan, 1965, Table 18, ll. 1-3, p. 176). ${ }^{18}$ The reserve requirement ratios and the rediscount rate are not held constant so that the marginal effect of interest rates on the reserve ratio can appear free of these entangling influences. Cagan does not separate the amount of member-bank borrowing, although interest rates affect member-bank borrowing and the demand for excess reserves in opposite ways, and the expected effect of interest rates is smaller for the sum than for the components. Nevertheless, he reaches the conclusion, by default, that cyclical changes in the reserve ratio reflect mainly "business conditions" and not interest rates. The large accumulation of excess reserves in the late thirties is dismissed in two sentences; "The further rise in the next two years 1938-1940, however, was much too large to be ascribed to the preceding changes in reserve requirements. Other factors seem to have been present" (Cagan, 1965, p. 201).

\section{CONCLUSION}

Determinants and Effects of Changes in the Stock of Money is a careful, detailed, often painstaking analysis of the factors determining changes in the money supply during the eighty-year period starting in 1875. The time span covers twenty cycles, of which six are severe depressions and two reflect the financing of major wars. Despite the scope of the book and the mass of detail, the reader is almost always aware of the direction in which the author is heading and of the larger questions to which he devotes much attention: Is the money supply a

\footnotetext{
18 Cagan writes: "The changes [caused by shifts between demand and time deposits] ranging from 1 to less than 3 percentage points explain relatively little of the actual changes [in the reserve ratio], except for the first period in which the actual change was small" (1965, p. 177). The three periods and the proportion of the change in the reserve ratio accounted for by changes in the time-deposit ratio are: (1) 1914-31, 38 per cent; (2) 1931-43, 30 per cent; (3) 1943-55, 17 per cent.
} 
passive factor, responding to the changes in the real sector of the economy? Or, are changes in the stock of money important causal factors?

Cagan's answer will satisfy neither the proponents of a (primarily) monetary theory of the cycle nor those who argue that money is a relatively unimportant cause of fluctuations. Even those who agree with Cagan, and me, that changes in money depend partly on output and price changes may be unwilling to accept his conclusion that changes in expenditures acting on the ratio of currency to money are the most important cause of mild cycles in the stock of money and an important determinant of the business cycle.

Although I believe that several of the main conclusions depend too heavily on the National Bureau method of analysis and cannot be accepted without major reservations, I recommend the book. Both the scope and the detail are impressive, and the book is a pleasure to read and to review.

\section{REFERENCES}

Brunner, Karl, and Meltzer, A. H. An Alternative Approach to the Monetary Mechanism. Washington: House Committee on Banking and Currency, August, 1964. (a)

- The Federal Reserve's Attachment to the Free Reserve Concept. Washington: House Committee on Banking and Currency, May, 1964. (b)

- "Some Further Investigations of Demand and Supply Functions for Money," $J$. Finance, XIX (May, 1964), 240-83. (c)

Cagan, Phillip. Determinants and Effects of Changes in the Stock of Money, 1875-1960. Princeton, N.J.: Princeton Univ. Press (for the National Bureau of Economic Research, 1965).

- "Changes in the Cyclical Behavior of Interest Rates," Rev. Econ. and Statis., XLVIII (August, 1966), 219-50.

Culbertson, J. M. "Friedman on the Lag in Effect of Monetary Policy," J.P.E., LXVIII, No. 6 (December, 1960), 617-21.

Currie, L. The Supply and Control of Money in the United States. 2d ed. Cambridge, Mass.: Harvard Univ. Press, 1935.

De Leeuw, Frank. "A Model of Financial Behavior," in J. Duesenberry et al. (eds.). The
Brookings Quarterly Econometric Model of the United States. Chicago: Rand-McNally \& Co., 1965.

French, D. R. "The Significance of Time Deposits in the Expansion of Bank Credit, 1922-28," J.P.E., XXXIX (1931), 759-82.

Friedman, Milton. "The Lag in Effect of Monetary Policy," J.P.E., LXIX, No. 5 (October, 1961), 447-66.

Friedman, Milton, and Schwartz, Anna J. A Monetary History of the United States, 18671960. Princeton, N.J.: Princeton Univ. Press (for the National Bureau of Economic Research), 1963.

- Trends and Cycles in the Stock of Money in the United States, 1867-1960. New York: Columbia Univ. Press (for the National Bureau of Economic Research) (forthcoming).

Kareken, J., and Solow, R. M. "Lags in Monetary Policy," in Commission on Money and Credit. Stabilization Policies. Englewood Cliffs, N.J.: Prentice-Hall, Inc., 1963.

Meltzer, A. H. "Monetary Theory and Monetary History," Schweizerische Zeitschrift Wolkwirtschaft und Statis., CI (December, 1965), 404-22. 
267. An Elementary Political and Economic Theory of the Expenditures of Local Covernments, by James L. Barr and Otto A. Davis. The Southern Economic Journal, October 1966.

268. Time-Dependent Delays at Traffic Merges, by D. P. Graver, Jr. Operations Research, September-October 1966.

269. Engineering Production Functions and Capital-Labor Substitution in Metal Machining: Comment, by Lester B. Lave. The American Economic Review, September 1966.

270. Management Sciences and Management-Some Requirements for Further Development, by $\Lambda$. Charnes and W. W. Cooper. Management Science, October 1968.

271 Project Selection in Industrial R. \& D: Problems and Decision Processes, by Richard Brandenburg. Chapter II, Research Program Effectivenese, H. D. Lerner, Ed., (Gordon \& Breach, New York, New York) 1966.

272. The Effects of Goal Difficulty on Performance: A Field Experiment, by Androw C. Stodry and Emanuel Kay. Behavioral Science, November 1966.

273. A Convex Approximant Method for Nonconvex Extensions of Geometric Programing. by A. Charnes and W. W. Cooper. Proceedings of the National Academy of Sclences, November 1966 .

274. A Mathematical Model of Policy Formation in a Democratic Society, by Otto A. Davis and Melvin Hinich. Monograph in Mathematical Applications in Political Science, II Joseph Bernd, (ed.) (Southern Methodist University) 1966.

275. Analyzing Product Profiles with Orthogonal Discriminant Functions, by William F. Massy. Business and Economic Statistics Section Proceedings of the American Statistical Association, August 1966.

276. Bias in the DJLA Caused by Stock Splits, by E. Eugene Carter and Kalman J. Cohen. Financial Analysts Journal, November-December 1966.

277. Organizational Choice: A Study of Pre- and Postdecision Processes, by Victor H. Vroom. Organizational Behavior and Human Performance, December 1966.

278. Optimal Level Debt Schedules for Municipal Bonds, by Kalman J. Cohen and Frederick S. Hammer. Management Science, November 1966.

279. Task Dependency of Organizational Centrality: Its Behavioral Consequences, by Claude Faucheux and Kenneth D. Mackenzie. Journal of Experimental Social Psychology, October 1966.

280. Job Vacancy Measurement, by Myron L. Josoph. The Journal of Human Resources, Fall 1966.

281. Monetary Rules: A New Look, by M. Bronfenbrenner. The Journal of Law and Economics, 1966.

282. Asymmetry between Bribes and Charges: Reply, by M. I. Kamien, N. L. Schwartz, and F. T. Dolbear. Water Resources Research, Fourth Quarter, 1966.

288. Financial and Budgetary Problems in the Large-Scale Public EDP System, by Andrew P. Stedry, Proceedings of the Second Annual Conference on Applications of E.D.P. System for State and Local Government, April 1966.

284. The Allocation, Characteristics, and Outcome of the Firm's Research and Development Portfolio: A Case Study, by Edwin Mansfield and Richard Brandenburg. The Journal of Business of the University of Chicago, October 1968.

285. The Shorter Work Week and the Labor Supply, by M. Bronfenbrenner and Jan Mossin. The Southern Economic Journal, January 1967.

286. Some Network Characterizations for Mathematical Programming and Accounting Approaches to Planning and Control, by $\Lambda$. Charnes and W. W. Cooper. The Accounting Review, January 1967.

287. Risk Orientation as a Predictor in the Prisoner's Dilemma; by F. Trenery Dolbear, Jr., and Lester B. Lave. The Journal of Conflict Resolution, December 1968.

288. Models and Modelling for Manpower Planning, by W. R. Dill, D. P. Gaver, and W. L. Weber. Management Science, December 1966.

289. The Benefits and Costs of Bank Mergers, by Kalman J. Cohen and Samuel Richardson Reid. Journal of Financial and Quantitative Analysis, December 1966.

290. Regression Yield Curves for U. S. Government Securities, by Kalman J. Cohen, Robert L. Kramer, and W. Howard Waugh. Management Science, December 1966.

291. Inconsistent Behavior in Lottery Choice Experiments, by F. Trenery Dolbear, Jr., and Lester B. Lave. Behavioral Science, January 1967.

292. Strategy, Organization Planning, and Changing Problems of Corporate Management, by Richard G. Brandenburg. Kommunikation, November 1966.

293. Analysis of Retailer Advertising Behavior, by William F. Massy and Ronald E. Frank. Journal of Marketing Research, November 1966. 
The present series begins with articles written by the faculty of the Graduate School of Industrial Administration and published during the 1957-58 academic year. Single copies may be secured free of charge from: Reprint Editor, G.S.I.A., Carnegie Institute of Technology, Pittsburgh, Pa. 15213. Additional copies are 50 cents each, unless otherwise noted.

(Continued)

294. Private and Public Consumption and Savings in the von Neumann Model of an Expanding Economy, by Oskar Morgenstern and Gerald L. Thompson. Kyklos, 1967.

295. Optimal Investment Policy and the Flexible Aocelerator, by Robert E. Lucas, Jr. International Economic Review, February 1967.

296. Motivational and Emotional Controls of Cognition, by Herbert A. Simon. Psychological Review, January 1967.

297. The Business School, A Problem in Organizational Design, by Herbert A. Simon. The Journal of Management Studies, February 1967.

298. Decomposition of Communication Netwarks, by Kenneth D. Mackenzie. Journal of Mathematical Psychology, February 1967.

299. The Use of Information Processing Languages in Psychology, by Herbert A. Simon. Les Modèles et la Formalisation du Comportement. Proceedings of the Colloques Internationaux Du Centre National De La Recherche Scientifique, July 1965.

300. The Possibility of Oversupply of Local "Public" Goods: A Critical Note, by William C. Brainard and F. Trenery Dolbear, Jr. The Journal of Political Economy, February 1967.

301. A Program of Research in Business Planning, by $H$. Igor Ansoff and Richard C. Brandenburg. Management Science, February 1967.

302. On the Theory of Optimum Externality, by F. Trenery Dolbear, Jr. The American Economic Review, March 1967.

303. A Note on Supplemental Appropriations in the Federal Budgetary Process (1), by Gary W. Bowman, Otto A. Davis, Henry J. Gailliot, and Alan C. Hess. Papers on Non-Market Decision Making, 1967.

304. The Job of a College President, by Herbert Simon. The Educational Record, Winter 1967.

305. An Empirical Evaluation of Alternative Portfolio-Selection Models, by Kalman J. Cohen and Jerry A. Pogue. The Journal of Business of the University of Chicago, April 1967.

306. "Hard" and "Soft" Lines in Economic Development, by M. Bronfenbrenner. The Libyan Economic and Business Review, 1967.

307. Programs as Factors of Production, by Herbert A. Simon. Proceedings of the Nineteenth Annual Winter Meeting Industrial Relations Research Association, 1967.

308. Monopoly Rents, Wage Rates, and Union Wage Effectiveness, by Leonard A. Rapping. The Quarterly Review of Economics \& Business, Spring 1967.

309. Stock Averages, Stock Splits, and Bias, by E. Eugene Carter and Kalman J. Cohen. Financial Analysts Journal, May-June 1967.

310. Copper Prices; A Case Study of Guidepost Policy, by Robert C. Blattberg and Timothy W. McGuire. California Management Review, 1967.

311. Need and Value Shifts in College Training Groups, by Howard Baumgartel and Joel W. Goldstein. The Journal of Applied Behavioral Science, 1967.

312. The Use of Simulation in Selecting Branch Banks, by E. Eugene Carter and Kalman J. Cohen. Industrial Management Review, Spring 1967.

313. Money Supply Revisited: A Review Article, by Allan H. Meltzer. The Journal of Political Economy, April 1967.

314. Operations Research in the Design of Management Information Systems, by Charles $\mathrm{H}$. Kriebel. Operations Research and the Design of Management Information Systems, John F. Pierce Jr., Editor, Fall 1966.

315. Coefficient Estimation in Quadratic Programming Models, by Charles H. Kriebel. Management Science, April 1967.

316. Self-Perception: The Dependent Variable of Human Performance, by Daryl J. Bem, Organizational Behavior and Human Performance, May 1967.

317. Team Decision Models of an Inventory Supply Organization, by Charles H. Kriebel. Naval Research Logistics Quarterly, June 1965. 